\title{
PREPARATION, THERMOANALYTICAL AND IR STUDY OF MIXED-LIGAND COMPLEXES FORMED IN WATER-1,2-ETHANEDIOL-COBALT(II)SULFATE SYSTEMS
}

\author{
I. Labádi ${ }^{1 *}$, L. Horváth ${ }^{1}$, G. Kenessey ${ }^{2}$ and G. Liptay ${ }^{2}$ \\ ${ }^{1}$ Department of Inorganic and Analytical Chemistry, University of Szeged, Dóm tér 7, 6720 Szeged, Hungary \\ ${ }^{2}$ Department of Inorganic Chemistry, Technical University of Budapest, Gellért tér 4, 1521 Budapest, Hungary
}

Parent and mixed-ligand cobalt(II) complexes of different compositions were prepared with water, sulfate ion and 1,2-ethanediol as ligands. The magnetic susceptibility data, the IR spectra and the thermoanalytical curves of the complexes were recorded. Oxygen atoms bound by one or two coordinate bonds to the metal ion, or by hydrogen-bonds were observed in the crystals pace.

Keywords: Co(II) complexes, 1,2-ethanediol, IR spectra, mixed-ligand complexes, thermoanalytical study

\section{Introduction}

It is well-known that a hydroxy $(\mathrm{OH})$ group, in an aliphatic organic compound is a relatively weak donor group in respect of complexation of metal ions. However, some natural or artificial polyalcohols (e.g. sugars or cyclodextrins) can often absorb and transport metal ions in vivo $[1,2]$, which suggests the important coordinating ability of the $\mathrm{OH}$ groups. The most important chemical factor in these processes is complexation through the occurence of coordination between $\mathrm{OH}$ groups and metal ions. To clarify the nature of the coordination between $\mathrm{OH}$ groups and metal ions, complexes of 1,2-ethanediol(Gl) with $\mathrm{Cu}(\mathrm{II}), \mathrm{Fe}(\mathrm{II}), \mathrm{Zn}(\mathrm{II}), \mathrm{Ca}(\mathrm{II}), \mathrm{Mg}(\mathrm{II}), \mathrm{Cd}(\mathrm{II}), \mathrm{Mn}(\mathrm{II})$ and $\mathrm{Ni}$ (II) ions were earlier prepared and investigated by thermoanalytical, magnetic susceptibility, IR spectroscopic and X-ray diffraction methods [3-9].

To complete this study from the aspect of theoretical considerations of the Irving-Williams series of metal ions [10], $\mathrm{Co}$ (II) complexes of 1,2-ethanediol have now been prepared and investigated by the above-mentioned methods. The metal ion source was $\mathrm{CoSO}_{4} \cdot 7 \mathrm{H}_{2} \mathrm{O}$, so that our earlier studies the coordination ability of 1,2-ethanediol, water and sulfate ion could be continued [3-9].

\section{Experimental}

Preparation of complexes

For the preparation of the complexes, $\mathrm{CoSO}_{4} \cdot 7 \mathrm{H}_{2} \mathrm{O}$, 1,2-ethanediol and water were mixed, the solid compound was dissolved, and different methods were used to obtain solid complexes. The solid complexes were stored under $\mathrm{CaCl}_{2}$ or $\mathrm{P}_{2} \mathrm{O}_{5}$ in a desiccator. The preparation was repeated several times to check the reproducibility. The details were as follows:

$\mathrm{Co}(\mathrm{Gl})_{1-1.5}\left(\mathrm{H}_{2} \mathrm{O}\right)_{4-5} \mathrm{SO}_{4}$ (complex 1)

$20 \mathrm{~g}$ of $\mathrm{CoSO}_{4} \cdot 7 \mathrm{H}_{2} \mathrm{O}$ was dissolved in $10 \mathrm{~cm}^{3}$ of 1,2-ethanediol and $2 \mathrm{~cm}^{3}$ of water. In a refrigerator, solid crystals separated out during 1 day, the composition of which was close to that of the starting material, $\mathrm{CoSO}_{4} \cdot 7 \mathrm{H}_{2} \mathrm{O}$, together with a small amount of 1,2-ethanediol. This solid was filtrated off and discarded. On the continued cooling, solid crystals precipitated out from the filtrate, these were separated by filtration, washed with ethanol and stored over $\mathrm{CaCl}_{2}$ in a desiccator.

$\mathrm{Co}(\mathrm{Gl})_{1.5}\left(\mathrm{H}_{2} \mathrm{O}\right)_{4} \mathrm{SO}_{4}$ (complex 2)

$5 \mathrm{~g}$ of $\mathrm{CoSO}_{4} \cdot 7 \mathrm{H}_{2} \mathrm{O}$ and $5 \mathrm{~cm}^{3}$ of 1,2-ethanediol were mixed at room temperature. After some hours the mixture became a slurry. The precipitated solid compound was separated by filtration, washed with ethanol, dried and stored over $\mathrm{CaCl}_{2}$ in a desiccator.

$\mathrm{Co}(\mathrm{Gl})_{2}\left(\mathrm{H}_{2} \mathrm{O}\right)_{2-3} \mathrm{SO}_{4}$ (complex 3)

$5 \mathrm{~g}$ of $\mathrm{CoSO}_{4} \cdot 7 \mathrm{H}_{2} \mathrm{O}$ and $10 \mathrm{~cm}^{3}$ of 1,2-ethanediol were mixed at room temperature. The mixture was filtered to remove the undissolved solid material. A mixture of ethanol $\left(10 \mathrm{~cm}^{3}\right)$ and benzene $\left(20 \mathrm{~cm}^{3}\right)$ was then added to the filtrate during stirring. The precipitated solid compound was separated by filtration, washed with ethanol, dried and stored over $\mathrm{CaCl}_{2}$ or/and $\mathrm{P}_{2} \mathrm{O}_{5}$ in a desiccator. 


\section{$\mathrm{Co}(\mathrm{Gl})_{3}\left(\mathrm{H}_{2} \mathrm{O}\right)_{3} \mathrm{SO}_{4}$ (complex 4)}

$5 \mathrm{~g}$ of $\mathrm{CoSO}_{4} \cdot 7 \mathrm{H}_{2} \mathrm{O}$ was dissolved in $10 \mathrm{~cm}^{3}$ of 1,2-ethanediol by heating $\left(70-80^{\circ} \mathrm{C}\right)$. The solution was stored over $\mathrm{CaCl}_{2}$ in a vacuum desiccator. The pink crystals that precipitated from the solution after some days, were separated by filtration and washed with ethanol and ether. The solid material was stored over $\mathrm{CaCl}_{2}$ in a desiccator.

$\mathrm{Co}(\mathrm{Gl})_{3} \mathrm{SO}_{4}$ (complex 5)

$5 \mathrm{~g}$ of $\mathrm{CoSO}_{4} \cdot 7 \mathrm{H}_{2} \mathrm{O}$ was dissolved in $10 \mathrm{~cm}^{3}$ of 1,2 -ethanediol by heating $\left(70-80^{\circ} \mathrm{C}\right)$. The solution was heated to evaporate the water content of the mixture, and then stored over $\mathrm{P}_{2} \mathrm{O}_{5}$ in a vacuum desiccator. Solid pink crystals precipitated from the solution after some days; they were separated by filtration and washed with ethanol and ether. The solid material was stored over $\mathrm{P}_{2} \mathrm{O}_{5}$ in a desiccator.

\section{Determination of composition}

The metal, 1,2-ethanediol and water contents of the complexes were determined by classical analytical methods (complexometry, Malaprade reaction and Karl-Fischer method). The analytically determined compositions were checked thermoanalytically.

\section{Thermoanalytical studies}

The thermal decompositions of the complexes were investigated with a MOM OD-2 derivatograph at a heating rate of $2^{\circ} \mathrm{C} \mathrm{min}^{-1}$. The mass of the investigated samples was 100-200 mg. The measurements were carried out in Pt crucibles in an air or nitrogen atmosphere and $\alpha-\mathrm{Al}_{2} \mathrm{O}_{3}$ was used as reference substance. Decomposition intermediates were prepared by stopping the heating process at appropriate temperatures and their compositions were determined by analytical methods.

\section{IR study}

The IR spectra of the complexes were taken in nujol in the interval $400-4000 \mathrm{~cm}^{-1}$ with a DIGILAB instrument. The characteristic bands were utilized to determine the coordination modes of the ligand, water molecules and sulfate ion.

\section{Magnetic susceptibility measurements}

The magnetic susceptibilities of the complexes were measured by the Faraday method, using $\mathrm{CuSO}_{4}$ as a reference compound. A Bruker M15 magnet and a Sartorius microbalance were used.

\section{Results and discussion}

\section{Preparation and compositions of complexes}

To prepare the cobalt - 1,2-ethanediol complexes, we primarily used the common methods, applied earlier to prepare other 1,2-ethanediol complexes [3-9]. The basic idea was to vary the temperature of the preparation, the ratio of the reactants, and the conditions of the storage of the prepared complexes. In contrast with the other 1,2-ethanediol metal complexes (e.g. those of $\mathrm{Cu}(\mathrm{II})$, $\mathrm{Fe}(\mathrm{II}), \mathrm{Zn}(\mathrm{II})$ and $\mathrm{Ni}(\mathrm{II})[3-6,9])$, these methods of preparation led to several complexes. Accordingly, we attempted a new way to obtain complexes: by adding an ethanol+benzene mixture (as a water-attractive agent) to a solution of cobalt sulfate and 1,2-ethanediol, the water content of the complexes could be decreased. This mode of preparation resulted in a complex with special thermal behaviour (complex $\mathbf{3}$ ).

The compositions of complexes $\mathbf{1}$ and $\mathbf{3}$ are uncertain, varying somewhat in the course of repeated experiments, and the composition was also strongly dependent on the condition of storage.

\section{Magnetic susceptibility measurements}

The magnetic data on the complexes are shown in Table 1 . The experimentally determined $\mu_{\text {eff }}$ values are higher than the theoretical value for high-spin complexes of the cobalt(II) ion (3.83), and an octahedral coordination sphere around the cobalt(II) ion may be suggested for all of the complexes [11].

It was found that the magnetic susceptibility data followed the Curie-Weiss law. According to the $\mathrm{Cu}-$ rie constant $(\Theta)$ values, all the complexes participate in antiferromagnetic interactions. This magnetic be-

Table 1 Magnetic data on the investigated complexes

\begin{tabular}{lrccc}
\hline Complex & $\Theta /{ }^{\circ} \mathrm{C}$ & $\mathrm{C}$ & $\mu_{\text {eff }}$ & $R$ \\
\hline $\mathbf{1}$ & 3.23 & 3.33 & 5.18 & 0.999 \\
$\mathbf{2}$ & -10.82 & 3.24 & 5.11 & 0.997 \\
$\mathbf{3}$ & -8.62 & 3.20 & 5.08 & 0.996 \\
$\mathbf{4}$ & -17.85 & 3.30 & 5.17 & 0.997 \\
$\mathrm{CoSO}_{4} \cdot 7 \mathrm{H}_{2} \mathrm{O}$ & -16.12 & 3.28 & 5.15 & 0.996 \\
\hline
\end{tabular}


Table 2 Characteristic IR bands of complexes

\begin{tabular}{|c|c|c|c|c|c|c|}
\hline \multirow{3}{*}{$\begin{array}{l}\text { Complex } \\
1,2 \text {-ethanediol }\end{array}$} & \multicolumn{2}{|c|}{ Bands of $\mathrm{SO}_{4}^{2-}$} & \multirow{2}{*}{\multicolumn{2}{|c|}{$\begin{array}{c}\text { Bands of } \mathrm{CO} \text { bonds } \\
v(\mathrm{C}-\mathrm{O})\end{array}$}} & \multirow{2}{*}{\multicolumn{2}{|c|}{$\begin{array}{c}\text { Bands of } \mathrm{H}_{2} \mathrm{O} \\
\delta\left(\mathrm{H}_{2} \mathrm{O}\right)\end{array}$}} \\
\hline & \multirow{2}{*}{$\begin{array}{l}v_{4} \\
-\end{array}$} & \multirow{2}{*}{$\frac{v_{2}}{-}$} & & & & \\
\hline & & & 1085 & 1045 & - & - \\
\hline 1 & 620 & $\begin{array}{l}1150 \\
1120\end{array}$ & $\begin{array}{l}1085 \\
1060\end{array}$ & 1040 & 1660 & \\
\hline 2 & $\begin{array}{l}630 \\
615\end{array}$ & $\begin{array}{l}1170 \\
1140 \\
1110\end{array}$ & $\begin{array}{l}1085 \\
1070\end{array}$ & $\begin{array}{l}1045 \\
1030\end{array}$ & 1660 & 1730 \\
\hline 3 & $\begin{array}{l}630 \\
610\end{array}$ & $\begin{array}{l}1170 \\
1110\end{array}$ & $\begin{array}{l}1085 \\
1070\end{array}$ & $\begin{array}{l}1045 \\
1030\end{array}$ & 1650 & 1730 \\
\hline 4 & 630 & $\begin{array}{l}1150 \\
1110\end{array}$ & $\begin{array}{l}1085 \\
1080\end{array}$ & 1040 & 1650 & - \\
\hline 5 & 630 & $\begin{array}{l}1170 \\
1130\end{array}$ & 1070 & 1030 & - & - \\
\hline $\mathrm{CoSO}_{4} \cdot 7 \mathrm{H}_{2} \mathrm{O}$ & 610 & 1130 & - & - & 1650 & - \\
\hline
\end{tabular}

haviour suggests a polymeric structure for all the complexes. Complex $\mathbf{5}$ is too sensitive to moisture for its magnetic behaviour to be determined.

\section{IR spectroscopic measurements}

In the IR spectra of the complexes, the bands of the water molecules, of the sulfate ion and the stretching vibration of the $\mathrm{C}-\mathrm{O}$ bonds could be identified, the values of the band maxima are presented in Table 2. For comparison, the IR bands of $\mathrm{CoSO}_{4} \cdot 7 \mathrm{H}_{2} \mathrm{O}$ are also listed.

Bands of the sulfate ion

A sulfate ion with $T_{\mathrm{d}}$ symmetry could be observed in $\mathrm{CoSO}_{4} \cdot 7 \mathrm{H}_{2} \mathrm{O}$, which correlates well with the structure of the molecule. In cobalt(II) sulfate heptahydrate, the sulfate ion is not coordinated to the cobalt(II) ions, it bound by hydrogen-bonds to water molecules [12]. In some 1,2-ethanediol complexes containing water molecules, the $v_{2}$ and $v_{4}$ stretching bands of the sulfate ion are split into two bands, indicating the $C_{3 \mathrm{v}}$ symmetry of the sulfate ion. This means that the sulfate ion is coordinated by 1 oxygen atom to the metal ion in these complexes.

\section{Bands of the water molecules}

The coordinated water molecules in the hexa- and heptahydrate give a band with maximum at $1650 \mathrm{~cm}^{-1}$ (deformation vibration). This band could be observed in all off the water-containing complexes too, which show that coordinated water molecules are present in these complexes. The weak band at $1730 \mathrm{~cm}^{-1}$ indicates the presence of water bound by hydrogen-bonds (moisture water).
Bands of the 1,2-ethanediol molecule

1,2-Ethanediol gives 2 strong bands, with maxima at 1085 and $1045 \mathrm{~cm}^{-1}$, assigned predominantly to the stretching vibration of the $\mathrm{CO}$ bond. Decreases in these band maxima are expected on coordination of the oxygen atom. This phenomenon can be observed in Table 2. In the IR spectra of complexes 1, 2, 3 and 4, one or both of the $\mathrm{CO}$ bands of free 1,2-ethanediol are to be seen, with 2 other bands close each of these bands (1070, 1060, 1040 and $\left.1030 \mathrm{~cm}^{-1}\right)$. These bands point to the presence of free and coordinated $\mathrm{OH}$ groups, i.e. the 1,2-ethanediol molecules act as monodentate and bidentate ligands.

The structure of the tris(1,2-ethanediol) complexes (like complex 5) is known [13-15]: the 1,2-ethanediol molecules act as bidentate chelate ligands and the sulfate ion is located in the outer coordination sphere, bound by hydrogen-bonds. In accordance with this structure, the 1070 and $1030 \mathrm{~cm}^{-1}$ bands could be assigned to a bidentate 1,2-ethanediol.

\section{Thermoanalytical behaviour of complexes}

On the basis of the thermoanalytical behaviour, the investigated complexes can be divided into three groups (A, B and C).

\section{Decomposition of type A}

Complexes $\mathbf{1}$ and $\mathbf{2}$ lose most of their water and 1,2-ethanediol molecules below 100 and $150^{\circ} \mathrm{C}$, respectively (Fig. 1). Analysis of the intermediates prepared at $200^{\circ} \mathrm{C}$, showed that approximately 0.5 molecule of ethyleneglycol and 1 molecule of water remained in the solid compound. When the heating was stopped at $250^{\circ} \mathrm{C}$, the product contained only 1 water molecule. The decomposition was accompa- 


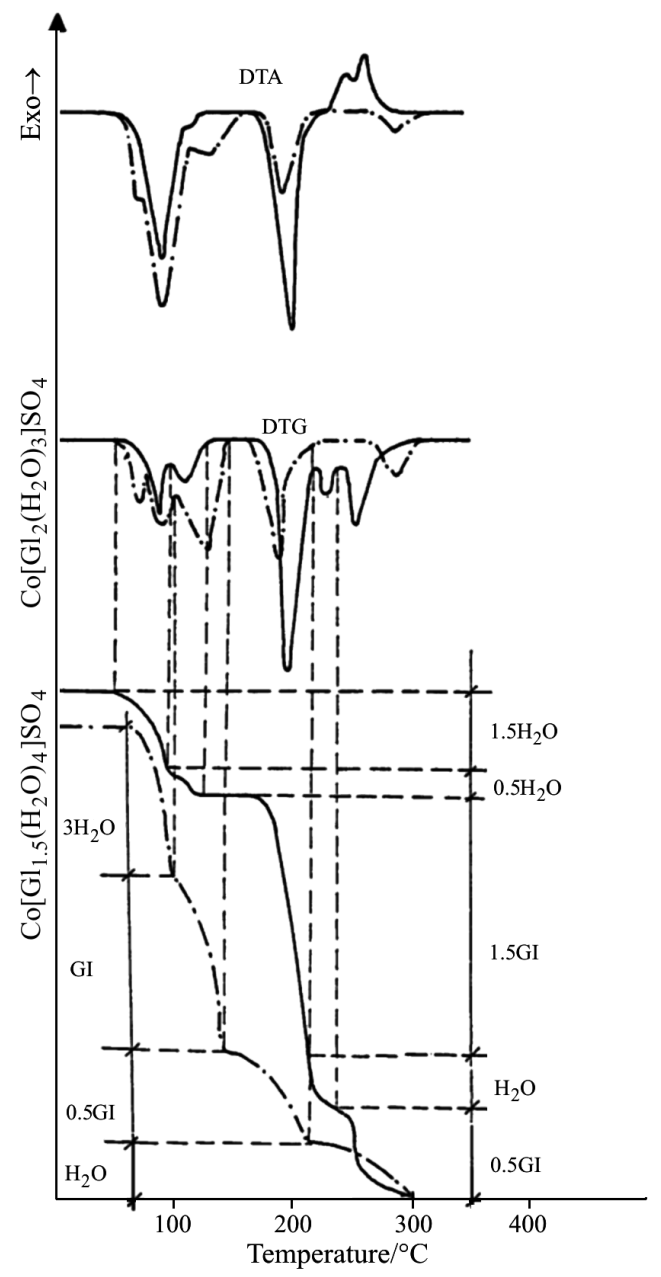

Fig. 1 Thermoanalytical curves of complexes of types - - - - A and $--B$

nied by endothermic effects and it was the same in air and in nitrogen atmosphere. The suggested decomposition scheme is as follows:

$$
\begin{gathered}
\mathrm{Co}(\mathrm{Gl})_{1-1.5}\left(\mathrm{H}_{2} \mathrm{O}\right)_{4-5} \mathrm{SO}_{4} \\
\downarrow \quad<150^{\circ} \mathrm{C} \\
\mathrm{Co}(\mathrm{Gl})_{0.5}\left(\mathrm{H}_{2} \mathrm{O}\right) \mathrm{SO}_{4} \\
\downarrow 180-220^{\circ} \mathrm{C} \\
\mathrm{Co}\left(\mathrm{H}_{2} \mathrm{O}\right) \mathrm{SO}_{4} \\
\downarrow 250-300^{\circ} \mathrm{C} \\
\mathrm{CoSO}_{4}
\end{gathered}
$$

\section{Decomposition of type B}

Complexes 3 and $\mathbf{4}$ lose water molecules (two and three, respectively) and 1,2-ethanediol (one in the case of the complex 4) molecules below $150^{\circ} \mathrm{C}$ and $\mathrm{Co}(\mathrm{Gl})_{2}\left(\mathrm{H}_{2} \mathrm{O}\right)_{0-1} \mathrm{SO}_{4}$ bis complexes are formed. This step is endothermic. The bis complexes decompose between 180 and $250^{\circ} \mathrm{C}$ in endothermic process to give $\mathrm{Co}(\mathrm{Gl})_{\mathrm{x}} \mathrm{SO}_{4}(x=0.5$ and 0.66$)$ and between 250 and $300^{\circ} \mathrm{C}$ in exothermic process to give $\mathrm{CoSO}_{4}$. The ratio of losses of masses is 2 to 1 in the case of the

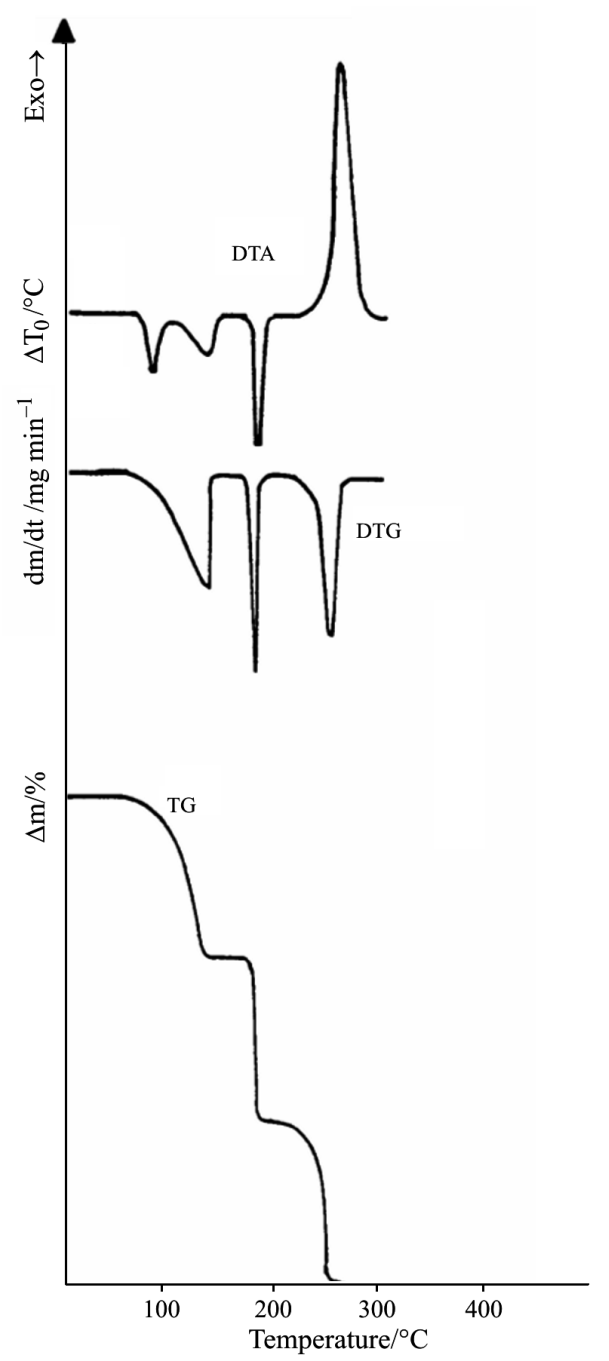

Fig. 2 Thermoanalytical curves of complexes of type C

complex 4 . The decomposition scheme for complex 3 is shown on Fig. 1 and for complex $\mathbf{4}$ is as follows:

$$
\begin{gathered}
\mathrm{Co}(\mathrm{Gl})_{3}\left(\mathrm{H}_{2} \mathrm{O}\right)_{3} \mathrm{SO}_{4} \\
\downarrow \quad<150^{\circ} \mathrm{C} \\
\mathrm{Co}(\mathrm{Gl})_{2} \mathrm{SO}_{4} \\
\downarrow 180-220^{\circ} \mathrm{C} \\
\mathrm{Co}(\mathrm{Gl})_{2 / 3} \mathrm{SO}_{4} \\
\downarrow 250-300^{\circ} \mathrm{C} \\
\mathrm{CoSO}_{4}
\end{gathered}
$$

In a nitrogen atmosphere, the decomposition is the same as in air, but the exothermic effect is then not observed. This points to the oxidation of 1,2-ethanediol in air at this temperature.

\section{Decomposition of type $\mathrm{C}$}

The tris(1,2-ethanediol) cobalt complex (5) decomposes in 3 steps: one molecule of the 1,2-ethanediol leaves the solid phase in each step. The third step is exothermic (Fig. 2). The decomposition scheme is as follows: 


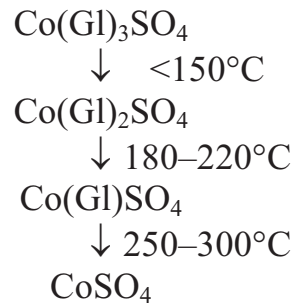

\section{Conclusions}

The magnetic and IR data indicate that in all the investigated cobalt complexes the sulfate ion, the water and the1,2-ethanediol molecules form an octahedral coordination sphere around the cobalt(II) ion. The water and the sulfate ion are coordinated as monodentate ligands, while in the case of 1,2-ethanediol there are several possibilities. The 1,2-ethanediol molecule may coordinate to a metal ion through 1 or 2 oxygen atoms (as a mono- or bidentate ligand). In the latter case, bridging or chelating binding occurs. Earlier studies found that, in the presence of water, 1,2-ethanediol always acts as a bridging ligand: chelation exists only in the water-free complexes [3-7]. The suggested polymeric structure for the mixed-ligand complexes (complexes 1-4) could be explain by the bridging coordination. This was also observed in other mixed-ligand metal complexes of 1,2-ethanediol ( $M=\mathrm{Mn}, \mathrm{Zn}, \mathrm{Cu}$ and $\mathrm{Ni}$ ) [3, 5-9]. In the tris(1,2-ethanediol) complex, the molecule forms a chelate and the structure is not polymeric [13-15].

It is known that cobalt sulfate heptahydrate loses 6 water molecules at approximately $100^{\circ} \mathrm{C}$ (depending on the heating rate). Only 1 water molecule can bind to metal sulfates above $150^{\circ} \mathrm{C}$; the water oxygen atom and the sulfate oxygen atoms complete the octahedral coordination sphere. In the mixed-ligand complexes, besides the water, the 1,2-ethanediol molecules can compete with the sulfate oxygen atoms for the coordination sites. This competition depends on the amounts of water and 1,2-ethanediol, and on the binding modes of water and 1,2-ethanediol in the complex.

From the aspect of thermal behaviour, complex 4 seems to be characteristic. On heating, this complex loses all its water below $150^{\circ} \mathrm{C}$ and a bis(1,2-ethanediol) complex is formed, which decomposes in 2 steps between 180 and $250^{\circ} \mathrm{C}$. In the first step, $4 / 3$ molecules of 1,2-ethanediol are released from the solid phase. Similar behaviour was observed in the case of $\mathrm{Zn}(1,2-$ ethanediol) $\mathrm{SO}_{4}$ ] [4] and pyridine or picoline complexes of nickel, cobalt, zinc and cadmium halides [16]. Such compositions of the intermediate were interpreted in terms of a polymeric and layered structure.

In complexes $\mathbf{1}$ and $\mathbf{2}$, there is not enough 1,2-ethanediol to form a bis complex on heating, so the intermediate (above $150^{\circ} \mathrm{C}$ ) contains both water and 1,2-ethanediol, in approximately the same ratio as present in the complexes (0.5-1).

In complex 4, there are more than 2 molecules 1,2-ethanediol, and thus the bis(1,2-ethanediol) intermediate complex is formed on heating above $150^{\circ} \mathrm{C}$. On further heating, this intermediate decomposes in a similar way as complex $\mathbf{3}$.

In complex 5, there is no water and the 1,2-ethanediol molecules are bound via chelation. On heating, the bis(1,2-ethanediol) complex also forms as an intermediate, which decomposes in a different way from the intermediates of complexes 3 and 4 . Because of the chelation of 1,2-ethanediol, there is no possibility for the formation of polymeric structure, which was suggested for the decomposition products of complexes 3 and 4 .

\section{References}

1 Biocoordination chemistry. Coordination Equilibria in Biological Active Systems (Ed. by K. Burger), Ellis Horwood Series in Inorganic Chemistry, Chichester 1989.

2 C. Margheritis, A. Martini and C. Sinistri, Z. Naturforsch., A52 (1966) 348.

3 I. Labádi, K. Burger, G. Liptay, M. Czugler and A. Kálmán, J. Thermal Anal., 31 (1986) 1171.

4 I. Labádi, G. Liptay, A. Horváth, L. Korecz, S. Papp and K. Burger, J. Thermal Anal., 32 (1987) 1575.

4 I. Labádi, G. Bernát, G. Kenessey, L. Párkányi, J. Mink and G. Liptay, Polyhedron, 11 (1992) 2975.

5 I. Labádi, L. Párkányi, G. Kenessey and G. Liptay, J. Cryst. Spectroscopic Res., 23 (1993) 333.

6 I. Labádi, L. Párkányi, R. Grobelny and J. Mrozinski, Polyhedron, 13 (1994) 2762.

7 I. Labádi, G. Kenessey and G. Liptay, J. Therm. Anal. Cal., 69 (2002) 487.

8 I. Labádi, I. Lakos, G. Kenessey and G. Liptay, J. Therm. Anal. Cal., 69 (2004) 829.

9 I. Labádi, G. Kenessey and G. Liptay, J. Therm. Anal. Cal., 82 (2005) 55.

10 H. Irving and R. J. Williams, J. Chem. Soc., (1953) 3192.

11 B. N. Figgis and J. Lewis, 'The Magnetic Properties of Transition Metal Complexes' in 'Progress in Inorganic Chemistry’, Ed. F. A. Cotton, Interscience, New York 1964, Vol. 6, p. 179.

12 Wyckow, Crystal Structures. Interscience, 1958. Vol. II. 10.

13 B.-M. Antti, B. K. S. Lundberg and N. Ingri, Acta Chem. Scand., 26 (1972) 3984.

14 B.-M. Antti, Acta Chem. Scand., A 30 (1976) 24.

15 B.-M. Antti, Acta Chem. Scand., A 30 (1976) 103.

16 G. Liptay, T. Wadstein and A. Borbély-Kuszman, J. Thermal Anal., 31 (1986) 845.

Received: March 30, 2005

In revised form: May 20, 2005

DOI: $10.1007 / \mathrm{s} 10973-005-7011-2$ 